\title{
KEKUATAN TEKAN MATERIAL SPOILER MOBIL BERBASIS KOMPOSIT ROTAN EPOKSI
}

\author{
Agustinus Purna Irawan, Adianto dan I Wayan Sukania \\ Jurusan Teknik Teknologi Industri Fakultas Teknik Universitas Tarumanagara \\ e-mail: agustinus@untar.ac.id
}

\begin{abstract}
This study aims to obtain the compressive strength of the material of a car spoiler product that was developed using materials from rattan fiber epoxy reinforced composites material. The car spoiler products are car accessories that also function as one of the equipment related to aerodynamics. The study was conducted by making test samples of rattan fiber epoxy reinforced composites and compared with the compressive strength of plastic spoiler materials obtained from the free market. The testing standard used is the compressive strength test of ASTM D 695. Based on the test results obtained compressive strength of spoiler made of plastic is $47.68 \pm 1.37 \mathrm{MPa}$ and rattan fiber epoxy reinforced composites material is $43.49 \pm 4.21 \mathrm{MPa}$, with a compressive strength difference of $8.8 \%$. The compressive strength of modeling results obtained a compressive strength of $47.97 \mathrm{MPa}$. This result is quite good and the difference is quite small, so the results of the study can be used as a reference for further product development.
\end{abstract}

Keywords: compressive strength, car spoiler products, rattan fiber epoxy reinforced composites

\section{PENDAHULUAN}

Spoiler merupakan salah satu produk asesoris yang banyak digunakan pada mobil. Fungsi spoiler tidak hanya sebagai asesoris, tetapi juga sebagai alat bantu untuk menghasilkan aerodinamika mobil yang baik, khususnya pada kecepatan yang tinggi [1-3]. Secara teknik aerodinamika, spoiler digunakan untuk mengatasi gaya hambat akibat kecepatan tinggi, sehingga mobil dapat melaju dengan kencang dan stabil. Fungsi aerodinamika ini diuji dalam pengujian aerodinamika di wind tunnel atau terowongan angin dan pengujian jalan [4-6].

Produk spoiler yang ada saat ini banyak dibuat dari bahan plastik khusus yang dikenal dengan plastik ABS atau dengan menggunakan bahan komposit berbasis serat gelas. Pada penelitian ini, dikembangkan spoiler berbasis komposit serat rotan dengan matriks epoksi. Tujuannya adalah memnghasilkan produk alternatif yang lebih ramah lingkungan dengan memanfaatkan potensi alam Indonesia yang kaya akan rotan. Pengembangan produk spoiler mobil dengan memanfaatkan potensi lokal, selaras dengan isu tentang lingkungan, dimana saat ini berkembang pandangan baru tentang go green, kembali ke alam (back to nature) dan isu tentang pengurangan limbah yang berbahaya [6-13].

Fokus penelitian adalah menghasilkan karakteristik bahan komposit serat rotan epoksi khususnya kekuatan tekan dan dibandingkan dengan bahan spoiler berbasis plastik ABS yang diperoleh dari pasaran bebas. Kekuatan tekan sangat diperlukan karena pada saat pemasangan spoiler pada mobil, dilakukan proses penyambungan dengan menggunakan baut yang diberikan tekanan yang cukup kuat, sehingga tidak mudah lepas. Tekanan yang besar dapat merusak bahan spoiler jika tidak diperhitungkan dengan baik [14-15].

\section{METODE PENELITIAN}

Penelitian pengembangan komposit serat rotan epoksi bertujuan untuk menghasilkan karakteristik mekanik khususnya kekuatan tekan bahan komposit berpenguat serat rotan dengan matriks epoksi, membandingkan karakteristik mekanik produk spoiler mobil berbahan plastik ABS, merancang proses manufaktur produk spoiler berbahan komposit serat rotan, dan menghasilkan produk spoiler berbasis komposit serat rotan [15].

Tahapan penelitian meliputi hal-hal sebagai berikut:

(1) Pembuatan bahan komposit berpenguat serat rotan dengan matriks epoksi.

(2) Pembuatan sampel uji bahan komposit serat rotan

(3) Pembuatan sampel uji bahan spoiler berbasis plastik ABS. 
(4) Pengujian tekan (Compressive): ASTM D695

(5) Analisis hasil pengujian dan rekomendasi.

Pembuatan sampel uji komposit serat rotan epoksi dilakukan dengan menggunakan bahan serat rotan kontinyu yang dianyam menjadi lembaran. Ukuran serat rotan adalah tebal $2 \pm 0,3 \mathrm{~mm}$ dan lebar $4 \pm 0,2 \mathrm{~mm}$. Lebar ayaman serat rotan sebesar 500 x $700 \mathrm{~mm}$. Ayamanan serat rotan selanjutnya direndam dalam larutan alkohol 90\% selama 30 menit, kemudian dikeringkan dalam suhu kamar. Tujuannya adalah untuk menghilangkan kotoran dan membersihkan getah yang masih menempel dalam serat rotan tersebut. Selanjutnya dilakukan proses laminasi dengan matriks epoksi, dimana perbandingkan antara epoksi dan hardener sebanyak 1:1. Proses laminasi serat rotan satu lapis tersebut dilakukan dengan cara diletakan dicetakan positif dari bahan semen gipsum yang telah dilapisi oleh plastik supaya tidak bocor, kemudian dituang matriks epoksi secara perlahan dan dilakukan proses tekan dan vakum, sehingga matriks epoksi dapat membasahi seluruh serat dan mengikat serat dengan kuat. Proses tekan dan vakum untuk menghilangkan terjadinya void pada komposit yang sedang diproduksi. Setelah selesai, bahan komposit serat rotan epoksi kemudian dikeringkan dalam suhu kamar selama 4 (empat) hari sampai mengeras dan siap untuk dilakukan pengujian [12, 16-17].

Proses pembuatan sampel uji dengan cara memotong komposit serat rotan epoksi yang sudah kering, sesuai dengan ukuran sampel uji mengacu standar pengujian yang akan dilakukan. Sebelum diuji, sampel uji tidak dilakukan perlakuan khusus, hanya disesuaikan dengan ukuran yang diperlukan, kemudian dilakukan pengujian.

Sampel uji bahan plastik ABS dibuat dengan cara memotong langsung dari produk spoiler yang dibeli dari pasaran asesoris yang dijual bebas. Produk spoiler yang dibeli dan dijadikan sampel uji merupakan produk spoiler yang banyak digunakan pada mobil yang paling banyak digunakan oleh masyarakat luas. Pembuatan sampel uji mengacu pada standar pengujian yang tekan.

\section{HASIL DAN PEMBAHASAN}

\section{Hasil uji tekan sampel uji bahan spoiler mobil dari plastik ABS}

Pengujian tekan bahan spoiler mobil dari plastik ABS yang dijual di pasaran dilakukan dengan menggunakan standar ASTM D695. Sampel uji dibuat dengan memotong dari produk spoiler yang sudah jadi dan dijual bebas di pasaran. Hasil pengujian tekan sebagai berikut:
Mesin
: Universal Testing AGS-G
Test speed $\quad: 1,3 \mathrm{~mm} / \mathrm{min}$
Kondisi ruang : $23^{0} \mathrm{C}, 52 \% \mathrm{RH}$
Standard : ASTM 695
Pretension : 0,5 $\mathrm{MPa}$
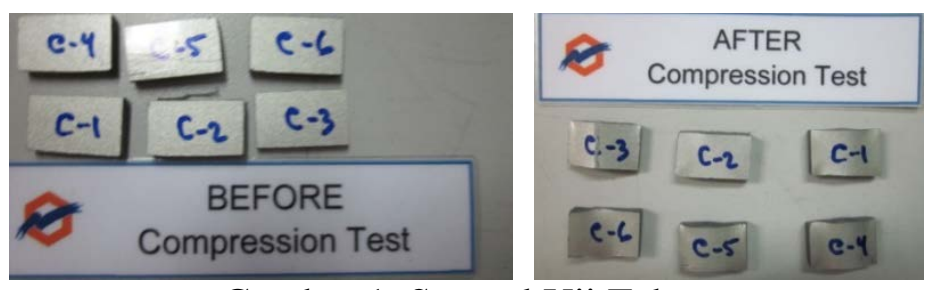

Gambar 1. Sampel Uji Tekan

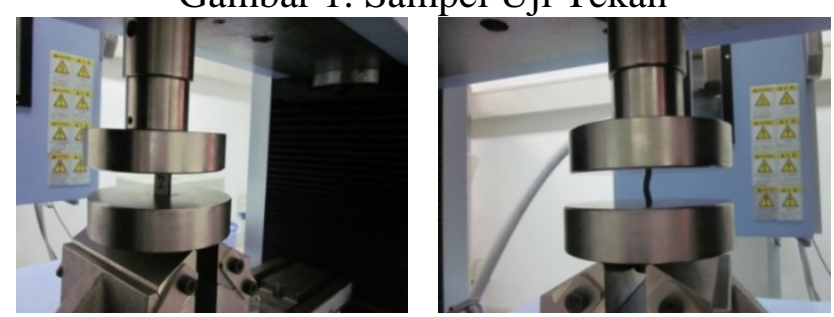

Gambar 2. Proses Uji Tekan 
Tabel 1. Hasil Pengujian Tekan Bahan Plastik ABS

\begin{tabular}{cccc}
\hline Sampel & $\begin{array}{c}\text { Tebal } \\
(\mathbf{m m})\end{array}$ & $\begin{array}{c}\text { Lebar } \\
(\mathbf{m m})\end{array}$ & $\begin{array}{c}\text { Kekuatan Tekan } \\
\text { (MPa) }\end{array}$ \\
\hline Sampel 1 & 3,65 & 12,29 & 48,58 \\
Sampel 2 & 4,01 & 12,13 & 47,85 \\
Sampel 3 & 2,74 & 12,02 & 46,60 \\
Sampel 4 & 3,61 & 12,35 & 45,79 \\
Sampel 5 & 4,05 & 11,83 & 47,60 \\
Sampel 6 & 3,73 & 12,41 & 49,62 \\
\hline Average & 3,93 & 12,17 & 47,68 \\
SD & 0,47 & 0,22 & 1,37 \\
\hline
\end{tabular}

\section{Hasil Uji Tekan Sampel Uji Bahan Spoiler Mobil dari Komposit Serat Rotan Epoksi}

Pengujian tekan bahan spoiler mobil dari Komposit Serat Rotan Epoksi yang dimanufaktur dengan proses laminasi, dengan diberikan tekanan dan vakum, dilakukan dengan menggunakan standar ASTM 695. Hasil pengujian tekan sebagai berikut:

Mesin : Universal Testing AGS-G

Test speed $\quad: 1.3 \mathrm{~mm} / \mathrm{min}$

Kondisi ruang : $23^{0} \mathrm{C}, 52 \% \mathrm{RH}$

Standard : ASTM 695

Pretension : 0,5 MPa
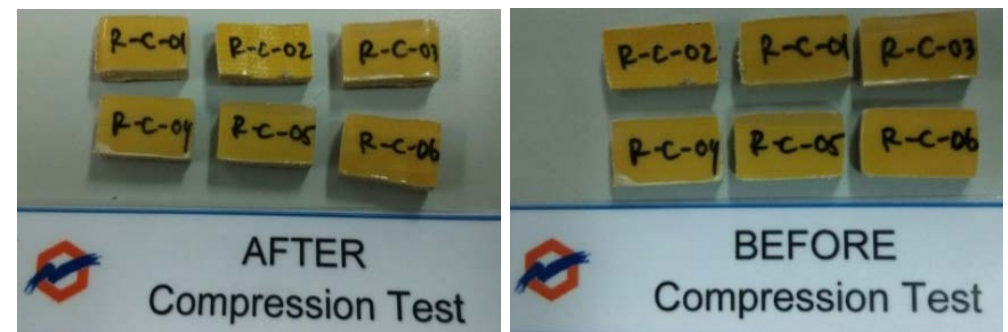

Gambar 3. Sampel Uji Tekan

Tabel 2. Hasil Pengujian Tekan Komposit Serat Rotan Epoksi

\begin{tabular}{cccc}
\hline Sampel & Tebal (mm) & Lebar (mm) & $\begin{array}{c}\text { Kekuatan } \\
\text { Tekan (MPa) }\end{array}$ \\
\hline Sampel 1 & 4,38 & 11,75 & 30,94 \\
Sampel 2 & 4,53 & 12,12 & 34,56 \\
Sampel 3 & 4,45 & 12,11 & 34,21 \\
Sampel 4 & 4,32 & 12,11 & 34,88 \\
Sampel 5 & 4,12 & 12,36 & 43,49 \\
Sampel 6 & 4,67 & 12,33 & 34,39 \\
\hline Average & 4,45 & 12,13 & 35,41 \\
Maksimum & 4,67 & 12,36 & 43,49 \\
SD & 0,16 & 0,22 & 4,21 \\
\hline
\end{tabular}

Tabel 3. Perbandingan Kekuatan Tekan Hasil Pengujian

\begin{tabular}{cccc}
\hline Karakteristik Mekanik & Plastik ABS & $\begin{array}{c}\text { Komposit Serat } \\
\text { Rotan Epoksi }\end{array}$ & Perbedaan (\%) \\
\hline Kekuatan Tekan (MPa) & $47,68 \pm 1,37$ & $43,49 \pm 4,21$ & 8,8 \\
\hline
\end{tabular}

Perbedaan kekuatan tekan yang diperoleh cukup kecil yaitu sebesar 8,8\%. Hasil ini sangat baik dan berpotensi untuk ditingkatkan dengan proses manufaktur komposit yang baik. Pada penelitian ini, fokus kekuatan yang ingin dicapai adalah kekuatan tekan bahan spoiler karena terkait dengan gaya tekan baut pengikat yang harus ditahan oleh spoiler. Komposit serat rotan epoksi mempunya kekuatan tekan yang baik dengan perbedaan yang cukup kecil dibandingkan dengan 
kekuatan tekan bahan spoiler dari plastik ABS. Hasil sangat berpeluang untuk terus dikembangkan sampai menghasilkan bahan yang mempunyai kekuatan tekan yang mendekati kekuatan bahan referensi.

Sebagai data pembanding, dilakukan pemodelan pembebanan tekan dengan menggunakan bantuan software analisis kekuatan. Pada gaya tekan pengencangan baut sampai $300 \mathrm{~N}$ untuk setiap baut, tegangan tekan yang dialami oleh produk spoiler sebesar 6,88 MPa. Jika dibandingkan dengan gaya tekan yang menyebabkan bahan spoiler rusak pada gaya tekan sebesar $2110 \mathrm{~N}$, maka tegangan tekan dihasilkan sebesar 47,97 MPa. Dalam hal ini, berdasarkan pemodelan pembebanan, untuk pengencangan baut menggunakan beban $300 \mathrm{~N}$, maka safety factor (SF) sampai terjadinya kerusakan sebesar 7,3. Jika diasumsikan gaya tekan pengencangan baut sampai $1000 \mathrm{~N}$, maka safety factor (SF) yang dihasilkan sebesar 2,1. Hasil ini cukup baik dan dapat dilanjutkan untuk pengembangan berikutnya yaitu proses manufaktur prototipe produk spoiler menggunakan bahan komposit serat rotan epoksi pada tahap penelitian berikutnya.

Tabel 4. Perbanding Kekuatan Tekan Maksimum Bahan Spoiler dan Pemodelan

\begin{tabular}{lccc}
\hline Karakteristik Mekanik & Plastik ABS & $\begin{array}{c}\text { Komposit Serat } \\
\text { Rotan Epoksi }\end{array}$ & Pemodelan \\
\hline Kekuatan Tekan $(\mathrm{MPa})$ & $47,68 \pm 1,37$ & $43,49 \pm 4,21$ & 47,97 \\
\hline
\end{tabular}

Dari Tabel 4 terlihat bahwa perbedaan kekuatan tekan bahan plastik ABS dengan pemodelan dapat dikatakan sama, sehingga hasil pengujian valid. Sedangkan perbendaan dengan komposit serat rotan epoksi sebear $8.8 \%$ atau kurang dari 10\%, sehingga hasilnya juga cukup baik untuk dapat dikembangkan lebih lanjut.

\section{SIMPULAN}

Telah dilakukan penelitian unuk mendapatkan kekuatan tekan bahan komposit serat rotan epoksi dan dibandingkan dengan bahan spoiler berbahan plastik ABS. Pengembangan bahan komposit serat rotan epoksi ini sebagai bahan alternatif untuk mengembangkan produk spoiler berbasis komposit serat alam. Hasil penelitian menunjukan bahwa komposit serat rotan epoksi berpotensi untuk dikembangkan lebih lanjut sebagai bahan spoiler mobil. Kekuatan tekan yang diperoleh mendekati hasil uji tekan bahan spoiler berbasis bahan plastik ABS, dengan perbedaan 8.8\% dan telah divalidasi dengan pemodelan pembebanan berbasis software. Hasil ini menjadi salah satu referensi untuk pengembangan selanjutnya.

\section{DAFTAR PUSTAKA}

[1]. Sandy Minkah Kyei. Composite Car Rear Spoiler. Thesis. The Energy and Material Technology Department. Arcada University of Applied Sciences. 2014.

[2]. A. Sunanda, M. Siva Nayak. Analysis of NACA 2412 for Automobile Rear Spoiler Using Composite Material. International Journal of Emerging Technology and Advanced Engineering. Vol 3, Issue 1, January 2013. pp 236-242.

[3]. Hitoshi Fukuda, Kazuo Yanagimoto, Hiroshi China, Kunio Nakagawa. Improvement of Vehicle Aerodynamics by Wake Control. JSAE Review 16. 1995. pp 151-155.

[4]. G. M. Le Good, J. P. Howell, M. A. Passmore, A. Cogotti. A Comparison of On-Road Aerodynamic Drag Measurements with Wind Tunnel Data from Pininfarina and MIRA. International Congress and Exposition Detroit. Michigan. February 23-26. 1998.

[5]. Xu-xia Hu, Eric T.T. Wong. A Numerical Study On Rear-spoiler of Passenger Vehicle. World Academy of Science, Engineering and Technology 57. 2011. pp 636-641.

[6]. Ardiansyah Rahman, Ahmad Farid, Suriansyah. Pengaruh Penggunaan Spoiler Pada Model Kendaraan Sedan Terhadap Tekanan Hisap Dalam Terowongan Angin. PROTON. Vol. 6 No 1. 2014. pp 1-7. 
[7]. Soejono Tjitro, Agus Aria Wibawa. Perbaikan Karakteristik Aerodinamika pada Kendaraan Niaga. Jurnal Teknik Mesin Vol. 1, No. 2, Oktober 1999. pp. 108-115.

[8]. A. Balaji, B. Karthikeya, C. Sundar Raj. Bagasse Fiber - The Future Biocomposite Material: A Review. International Journal of ChemTech Research. Vol.7. No. 01. 2014. pp. 223-233.

[9]. Suddell B. Industrial Fibres: Recent and Current Developements. In Proceedings of the Symposium on Natural Fibres. 2009, p. 71 - 82.

[10]. Agustinus Purna Irawan, Tresna P. Soemardi Widjajalaksmi K., Agus H.S. Reksoprodjo. Komposit Laminate Rami Epoksi Sebagai Bahan Alternatif Socket Prsothesis. Jurnal Teknik Mesin UK. Petra. Vol. 11 No. 1. 2009. pp. 41-45.

[11]. Agustinus Purna Irawan, Tresna P. Soemardi Widjajalaksmi K., Agus H.S. Reksoprodjo. Pengaruh Kekerasan dan Kekasaran Permukaan Prototipe Socket Prosthesis Terhadap Kenyamanan Pengguna. Jurnal Teknik Mesin ITS. Vol. 11 No. 1. 2011. pp. 1-7.

[12]. Agustinus Purna Irawan, Tresna P. Soemardi Widjajalaksmi K., Agus H.S. Reksoprodjo. Tensile and Flexural Strength of Ramie Fiber Reinforced Epoxy Composites for Socket Prosthesis Application. International Journal of Mechanical and Material Engineering. Indexed by SCOPUS, Vol. 6 No. 1. April. 2011. pp. 46-50.

[13]. Agustinus Purna Irawan, I Wayan Sukania. Mechanical Characteristics Rattan Fiber Reinforced Epoxy Composites (RECO) as Above Knee Socket Prosthesis Materials. International Conference on Innovation in Polymer Science and Technology (IPST2011). Asian Polymer Association (APA) dan Indonesian Polymer Association (HPI). DenpasarBali, 28 Nov.-1 Des. 2011. ISBN: 978-602-7776-06-7. pp. 64-70

[14]. Agustinus Purna Irawan, I Wayan Sukania. Tensile and Impact Strength of Bamboo Fiber Reinforced Epoxy Composite as Alternative Materials for Above Knee Prosthesis Socket. Prosiding of $2^{\text {nd }}$ International Conference on Sustainable Technology Development. 31 October 2012. ISBN: 978-602-7776-06-7. pp: M.109-M.115.

[15]. Agustinus Purna Irawan, Adianto, I Wayan Sukania, M. Agung Saryatmo, Karakteritik Mekanik Material Spoiler Mobil Berbasis Bahan Plastik. Prosiding Seminar Nasional Teknologi dan Sains (SNTS) II 2016. pp. TM-25-TM-31.

[16]. G. Venkatesha Prasanna, K.Venkata Subbaiah. Modification, Flexural, Impact, Compressive Properties \& Chemical Resistance of Natural Fibers Reinforced Blend Composites. Malaysian Polymer Journal, Vol. 8 No. 1, 2013. pp 38-44.

[17]. L. Onal, Y. Karaduman. Mechanical Characterization of Carpet Waste Natural FiberReinforced Polymer Composites. Journal of Composite Materials. Vol. 43. 2009. pp. 1-18. 